Article

\title{
Biochemical Properties and Structure Analysis of a DAG-Like Lipase from Malassezia globosa
}

\section{Huan Xu ${ }^{1, \dagger}$, Dongming Lan ${ }^{1, \dagger}$, Bo Yang ${ }^{2}$ and Yonghua Wang ${ }^{1, *}$}

1 College of Light Industry and Food Sciences, South China University of Technology, Guangzhou 510640, China; E-Mails: xuhuanscut@163.com (H.X.); dmlanscut.edu.cn (D.L.)

2 School of Bioscience and Bioengineering, South China University of Technology, Guangzhou 510006, China; E-Mail: yangbo@scut.edu.cn

$\dagger$ These authors contributed equally to this work.

* Author to whom correspondence should be addressed; E-Mail: yonghw@scut.edu.cn; Tel./Fax: +86-20-8711-3842.

Academic Editor: Christo Z. Christov

Received: 8 December 2014 / Accepted: 9 February 2015 / Published: 4 March 2015

\begin{abstract}
Diacylglycerol (DAG)-like lipases are found to play an important role in the life sciences and industrial fields. A putative DAG-like lipase (MgMDL2) from Malassezia globosa was cloned and expressed in recombinant Pichia pastoris. The recombinant MgMDL2 was expressed as a glycosylated protein and purified into homogeneity by anion exchange chromatography. The activity of recombinant MgMDL2 was optimal at $15{ }^{\circ} \mathrm{C}$ and $\mathrm{pH} 6.0$, and it keeps over $50 \%$ of relative activity at $5{ }^{\circ} \mathrm{C}$, suggesting that $M g$ MDL 2 was a cold active lipase. $M g$ MDL2 retained over $80 \%$ of initial activity after incubation at 30 and $40{ }^{\circ} \mathrm{C}$ for $2.5 \mathrm{~h}$, but it was not stable at $50{ }^{\circ} \mathrm{C}$. Incubation of methanol and ethanol at a concentration of $30 \%$ for $2 \mathrm{~h}$ did not affect the recombinant enzyme activity, while metal ions, including $\mathrm{Ca}^{2+}, \mathrm{Mn}^{2+}$ and $\mathrm{Ni}^{2+}$, sharply inhibited the $\mathrm{MgMDL} 2$ activity at $5 \mathrm{mM}$ by $42 \%, 35 \%$ and $36 \%$, respectively. MgMDL2 exhibited a preference for medium chain-length esters with highest activity toward $p$-nitrophenyl caprylate, while it was active on mono- and diacylglycerol but not on triacylglycerol, indicating that it was a typical DAG-like lipase. By homology modeling, Phe278 was predicted to be involved in the preference of MgMDL2 for monoacyl- and diacyl-glyceride substrates, but not triglycerides.
\end{abstract}


Keywords: DAG-like lipases; Malassezia globosa; cold active enzyme; glycosylation; structure analysis

\section{Introduction}

DAG-like lipases, distinct from common triacylglycerol (TAG) lipases, are enzymes that exhibit specific activity on mono- and diacylglycerol (MAG and DAG) but not on TAG. They play an important role in regulating the physiological function in mammals. For example, they are found to be involved in the biosynthesis of the endocannabinoid 2-arachidonoylglycerol, an endogenous agonist of the CB1 receptor, which mediate neuronal communication [1]. DAG-like lipases are considered as a valuable target to develop therapeutic inhibitor for pain, inflammation, degenerative diseases, tissue injury, and cancer [2]. Besides that, they also are potential biocatalysts that could be used for modification of oil and fats $[3,4]$.

To date, few lipases including Penicillium camembertii (P. camembertii) U-150 [5], Penicillium cyclopium (P. cyclopium) [6], Fusarium sp. YM-30 [7], Aspergillus oryzae (A. oryzae) [8,9] and Malassezia globosa (M. globosa) [10], have been experimentally characterized as DAG-like lipases. Although sequence comparison analysis shows relatively low sequence identities to the TAG lipases, DAG-like lipases from $P$. camembertii U-150, A. oryzae and $M$. globosa are found to belong to Rhizomucor mihei (R. mihei) lipase like family (LED ID: abH23.01) at lipase engineering database by sequence analysis [11]. Both crystal structures from $M$. globosa (named as SMG1) and P. camembertii have been solved $[12,13]$. However, limited information was obtained from the $P$. camembertii lipase structure because the quality of the crystal data was affected by the twinning of the crystals. It is found that they have a canonical $\alpha / \beta$ hydrolase fold core which is a characteristic of all TAG-lipases family members [12]. By structural modeling analysis, a unique "bridge-like" structure was found to exist on the top of catalytic site of DAG-like lipases, which maybe limit the size of substrate allowed to enter the active site. This may contribute to their unique substrate selectivity [11].

TAG-lipases have been intensive investigation and many of them were commercial available, while the DAG-like lipases were rarely studied due to the limited number of them reported. To explore the industrial application of DAG-like lipases and fully understanding their molecular basis of substrate specificity, novel DAG-like lipases with unique properties need to be explored. In our previously study, a DAG-like lipase (SMG1) from M. globosa has been characterized by our lab [3]. In this study, a putative DAG-like lipase (XP_001732206, Name as MgMDL2), which showed high sequence identity (67\%) with that of SMG1, has been cloned, and its biochemical properties such as substrate selectivity, glycolysation, effect of $\mathrm{pH}$, temperature, organic solvents and metal ions on enzyme activity, were explored. Moreover, the molecular basis for the substrate specificity of MgMDL2 was discussed. 


\section{Results and Discussion}

\subsection{Sequence Analysis of MgMDL2}

The MgMDL2 gene is 915 bp in length, encoding a 304 aa protein. A deduced signal peptide region of 19 amino acids was found by analysis of SignalP 4.1. MgMDL2 has three Asn-Xaa-Thr/ser motifs (Asn102, 161 and 253) which are considered as potential glycosylation sites. According to the multiple alignment analysis, MgMDL2 was found to contain the characteristic active site of the $\alpha / \beta$ hydrolase fold enzyme. Catalytic residues (serine171, aspartate228, and histidine281) form the putative catalytic triad, and the nucleophilic serine residue locates at a highly conserved G-H-S-L-G pentapeptide motif (Figure 1). MgMDL2 exhibited high sequence identity with the SMG1 (67\%). It shares only 20\%, $20 \%$ and $19 \%$ sequence identity with those of DAG-like lipases from P. camembertii U-150 [5], P. cyclopium [6] and A. oryzae [9] (Figure 1), respectively, while MgMDL2 has a relative high sequence identity with that of TAG-lipases from R. miehei (28\%) [14] and Rhizopus oryzae (R. oryzae) (24\%) [15].

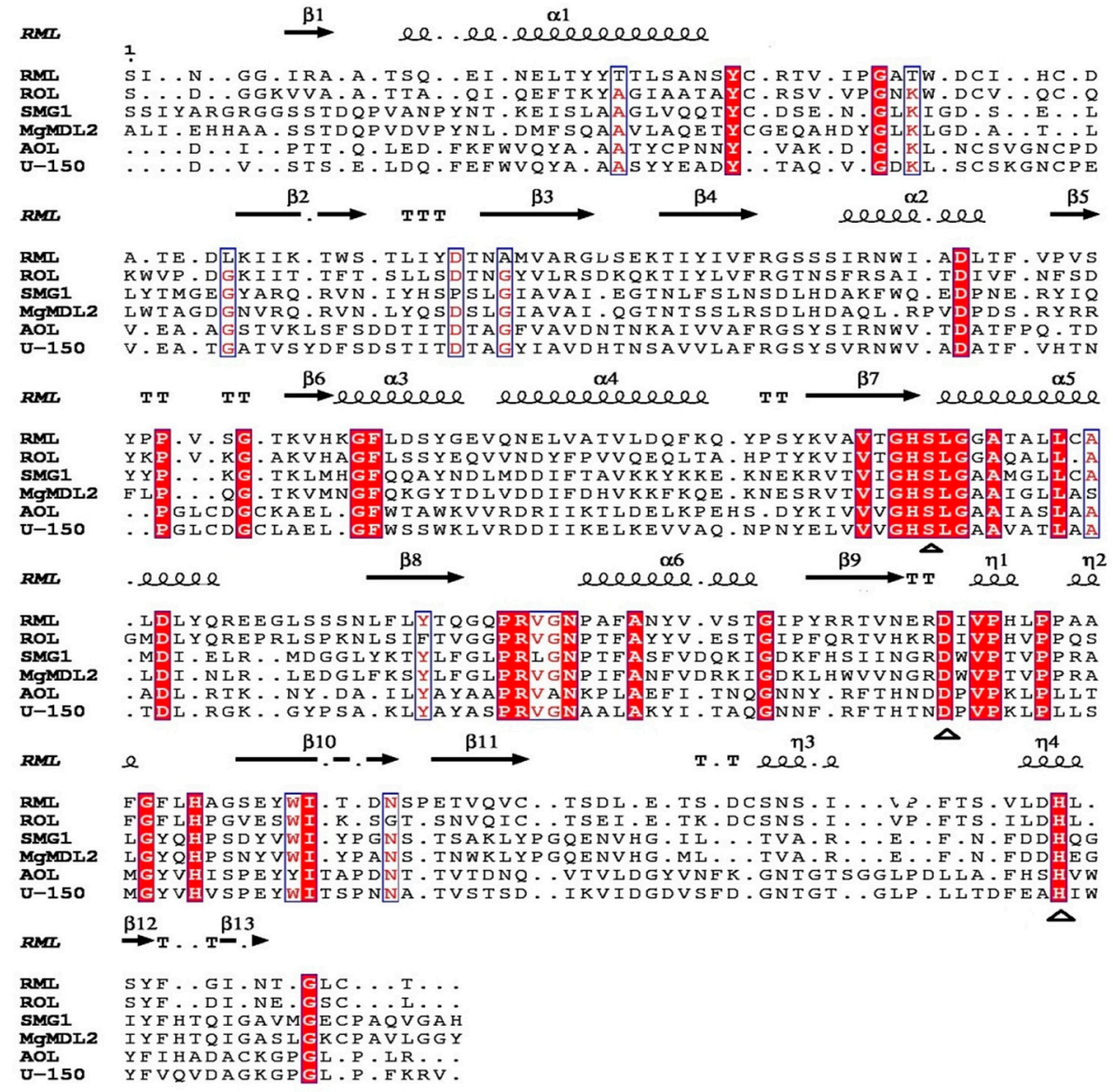

Figure 1. Multiple sequence alignment of $M g \mathrm{MDL} 2$. The lipases sequence included U-150 from P. camembertii U-150 (PDB: 1TIA_A), AOL from A. oryzae (XP_001823459 in GenBank), PCL from P. cyclopium (ADE87963 in GenBank), SMG1 from M. globosa (PDB: 3UUE), MgMDL2 from M. globosa (XP_001732206 in GenBank), RML from $R$. miehei (PDB ID: 4TGL) and ROL from $R$. oryzae (PDB ID: 1TIC). Identical residues were marked with red background and the highly conserved residues were showed as red font. The catalytic triads are indicated with triangle. 


\subsection{Expression and Purification of $M g M D L 2$}

The recombinant enzyme was purified by anion exchange chromatography into homogeneity with specific activity of $43.61 \mathrm{U} / \mathrm{mg}$ (pnp-caprylate as substrate). SDS-PAGE analysis of the purified MgMDL2 shows that it had an apparent molecular mass of $44 \mathrm{kDa}$ (Figure 2, lane 2), which was larger than the deduced one $(31 \mathrm{kDa}) . \mathrm{N}$-glycosylation is a major kind of protein posttranslational modification in Pichia pastoris (P. pastoris), and $70 \%-90 \%$ of the Asn residues in potential $N$-glycosylation sites (Asn-Xaa-Ser/Thr) will be modified by glycosylation [16]. MgMDL2 has three potential $N$-glycosylation sites; therefore it may be modified by $N$-linked glycosylation in yeast. To confirm that, glycopeptidase F which can specifically hydrolyze $N$-glycans from glycoprotein was used for treating the purified MgMDL2. After deglycosylation reaction, a protein band of $31 \mathrm{kDa}$ was observed (Figure 2, lane 3).
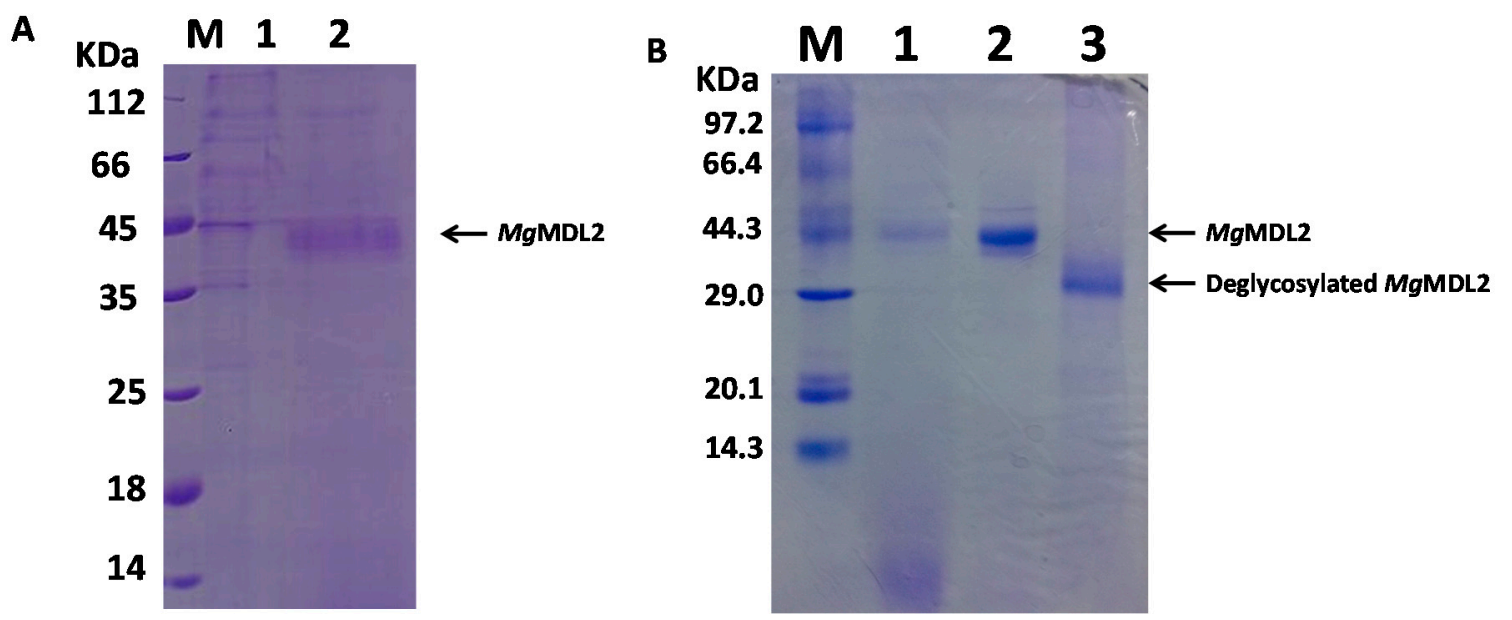

Figure 2. SDS-PAGE analysis of purification and deglycosylation of MgMDL2. (A) Detection of expression of MgMDL2. Lane M: marker; Lane 1: Supernatants of control P. pastoris X-33; Lane 2: Supernatants of recombinant $P$. pastoris X-33 having pGAPZaA-mgmdl2; (B) Purification and deglycosylation of MgMDL2. Lane 1: Supernatant of fermentation at 72 h; Lane 2: purified MgMDL2; Lane 3: Deglycosylated MgMDL2.

\subsection{Biochemical Properties of $M g M D L 2$}

To investigate whether MgMDL2 was a true DAG-like lipase and the potential as a biocatalyst in industry application, the biochemical properties of purified $M g$ MDL2 were studied.

\subsubsection{Effect of Temperature on Lipase Activity and Thermostability}

The optimum temperature of $M g \mathrm{MDL} 2$ was determined using $p$ np caprylate as substrate. Recombinant $M g M D L 2$ showed highest activity at $15^{\circ} \mathrm{C}$ (Figure 3A). Even at $5{ }^{\circ} \mathrm{C}, M g M D L 2$ kept over $50 \%$ activity.

The thermostability of $M g$ MDL2 was investigated at three different temperatures $\left(30,40\right.$ and $\left.50{ }^{\circ} \mathrm{C}\right)$ with increasing incubation time up to $2.5 \mathrm{~h}$. As shown in Figure 3B, the MgMDL2 was still active after incubation at 30 and $40{ }^{\circ} \mathrm{C}$, which retained above $89.6 \%$ and $84.4 \%$ of the initial activity, respectively. However, only $26 \%$ of initial activity was retained following incubation for $2.5 \mathrm{~h}$ at $50{ }^{\circ} \mathrm{C}$. 

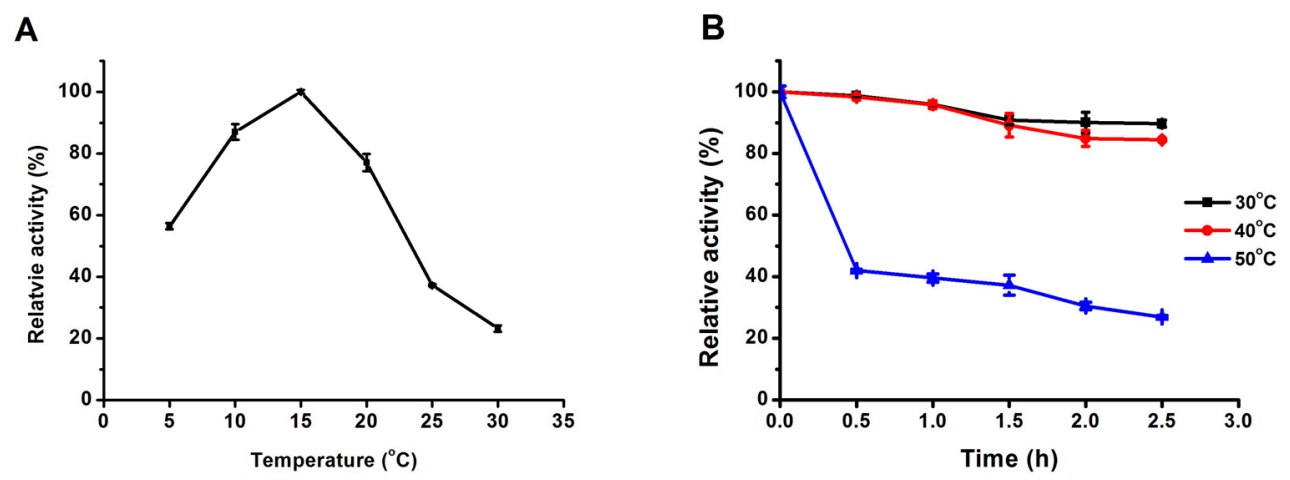

Figure 3. Effect of temperature on activity (A); and stability (B) of MgMDL2. (A) The purified $M g$ MDL2 was assayed at different temperatures $\left(5-30{ }^{\circ} \mathrm{C}\right)$. Activities are displayed as percentages of the maximum activity. Values are means \pm S.D. from three independent experiments; (B) The enzyme was assayed after incubation in various temperatures (30, 40 and $50{ }^{\circ} \mathrm{C}$ ) for $2.5 \mathrm{~h}$. Activity is displayed as percentages of the initial activity.

\subsubsection{Effect of $\mathrm{pH}$ on Lipase Activity and Stability}

The activity of MgMDL2 was measured over a $\mathrm{pH}$ range of 4.0-9.0. As shown at Figure 4A, MgMDL2 showed activity within a wide $\mathrm{pH}$ range $(\mathrm{pH} 4.0-7.0)$ with an optimal activity at $\mathrm{pH} 6.0$ while it was totally inactive at $\mathrm{pH} 8.0$ and 9.0. MgMDL2 found to be stable over $\mathrm{pH}$ 6.0-8.0 with residual activity over $60 \%$ of initial activity (Figure 4B).
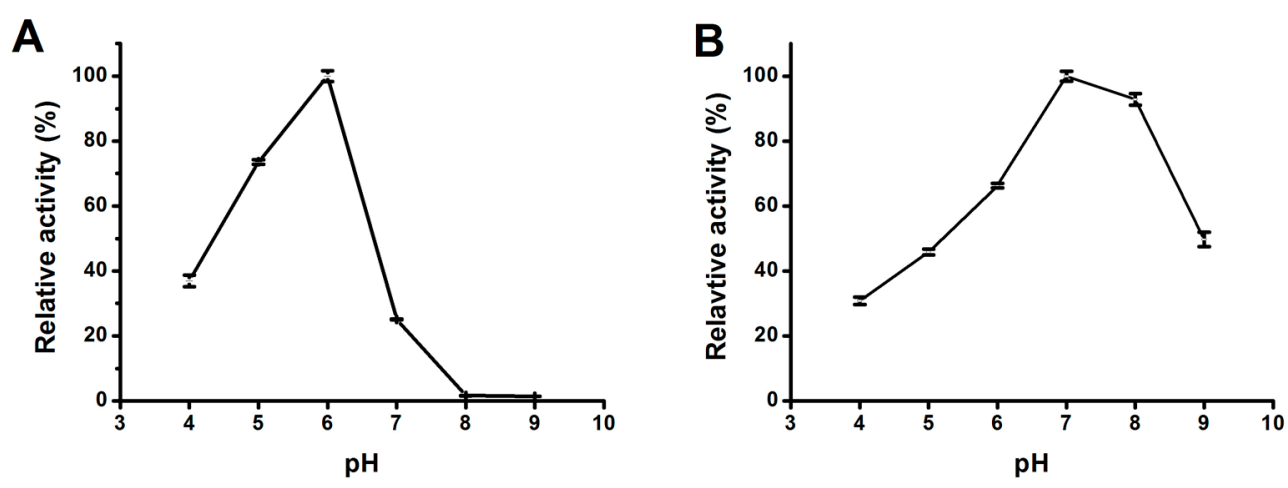

Figure 4. Effect of $\mathrm{pH}$ on the activity (A); and stability (B) of MgMDL2. Activities are shown as percentages of the maximum activity. Values are means \pm S.D. from three independent experiments.

\subsubsection{Effect of Chemicals and Organic Solvents on MgMDL2 Activity}

The influence of organic solvents and metal ions on the activity of MgMDL2 was investigated and the results are summarized in Table 1 . The enzyme was inhibited by isopropanol by $59 \%$ of initial activity, whereas it was not affected by methanol and ethanol, and weakly inhibited by acetone (retaining $85 \%$ of initial activity). To determine the effect of metal ions on MgMDL2 activity, the enzyme activities were tested in the presence of $5 \mathrm{mM}$ of various metal ions. All metal ions tested can inhibit enzyme activity. Among them, $\mathrm{Ca}^{2+}, \mathrm{Mn}^{2+}$ and $\mathrm{Ni}^{2+}$ sharply decreased the activity to $42 \%, 35 \%$ and $36 \%$ of initial activity, respectively. 
Table 1. Effects of various reagents on MgMDL2 activity.

\begin{tabular}{|c|c|c|}
\hline \multirow{2}{*}{ Reagents } & \multicolumn{2}{|c|}{ Relative Activity (\%) ${ }^{a}$} \\
\hline & $5 \mathrm{mM}$ & $30 \%(v / v)$ \\
\hline Control & 100 & 100 \\
\hline $\mathrm{Ni}^{2+}$ & $36 \pm 1$ & - \\
\hline $\mathrm{Zn}^{2+}$ & $61 \pm 4$ & - \\
\hline $\mathrm{Mn}^{2+}$ & $35 \pm 4$ & - \\
\hline $\mathrm{Mg}^{2+}$ & $53 \pm 4$ & - \\
\hline $\mathrm{Fe}^{2+}$ & $48 \pm 2$ & - \\
\hline $\mathrm{Ca}^{2+}$ & $42 \pm 1$ & - \\
\hline EDTA & $68 \pm 1$ & - \\
\hline Methanol & - & $98 \pm 2$ \\
\hline Ethanol & - & $97 \pm 4$ \\
\hline Acetone & - & $85 \pm 4$ \\
\hline Isopropanol & - & $41 \pm 2$ \\
\hline
\end{tabular}

- Not determined; ${ }^{\text {a }}$ Data are presented mean \pm standard deviation.

\subsubsection{Substrate Specificity of $M g$ MDL2}

The substrate preference of the MgMDL2 was firstly investigated using $p$-nitrophenyl ( $p$ np) ester with acyl chains of various lengths. As shown in Figure 5A, MgMDL2 has a strong preference for the hydrolysis of the ester bonds of medium chain-length esters with highest activity toward $p$ np caprylate (C8), while MgMDL2 displayed low activity toward the long chain-length esters (C16 and C18 acyl group).

For acylglycerol substrate, MgMDL2 was active toward the MAG and DAG, but inactive toward TAG (Figure 5B), indicating that the MgMDL2 was a true DAG-like lipase.
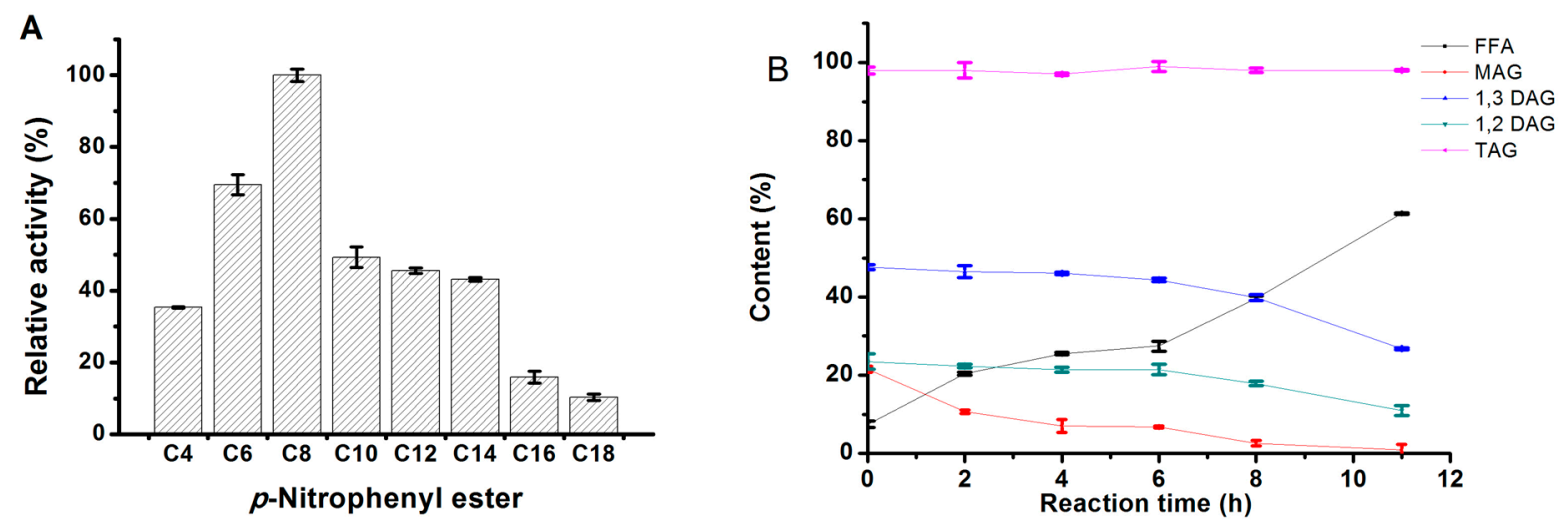

Figure 5. Determination of the substrate specificity of MgMDL2. (A) Activities on each $p n p$ ester are expressed as the percentage of $p$ np caprylate. Values are means \pm S.D. from three independent experiments; (B) Time course of hydrolysis of acylglycerols by MgMDL2. The hydrolysis reaction were performed using DAG-rich oil (23.47\% of 1,2-DAG, $47.60 \%$ of $1,3-\mathrm{DAG}, 21.51 \%$ of MAG and $7.42 \%$ of FFA) or TAG (camellia oil, $98 \%$ ) as substrate. The reaction products contents were analyzed by HPLC and showed in same curve. 


\subsection{Molecular Basis for Substrate Selectivity of $M g M D L 2$}

The modeling structure in open conformation led to the catalytic triad Ser171-Asp228-His281 exposing to the solvent (Figure 6). In the open conformation, the oxyanion hole was formed by residue Thr101 and Leu172 .The residues Trp53, Leu106, Leu110, Ala113, Phe138, Leu172, Pro201, Val230, Phe278, Ser293 and Leu294 were found to constitute the catalytic pocket.

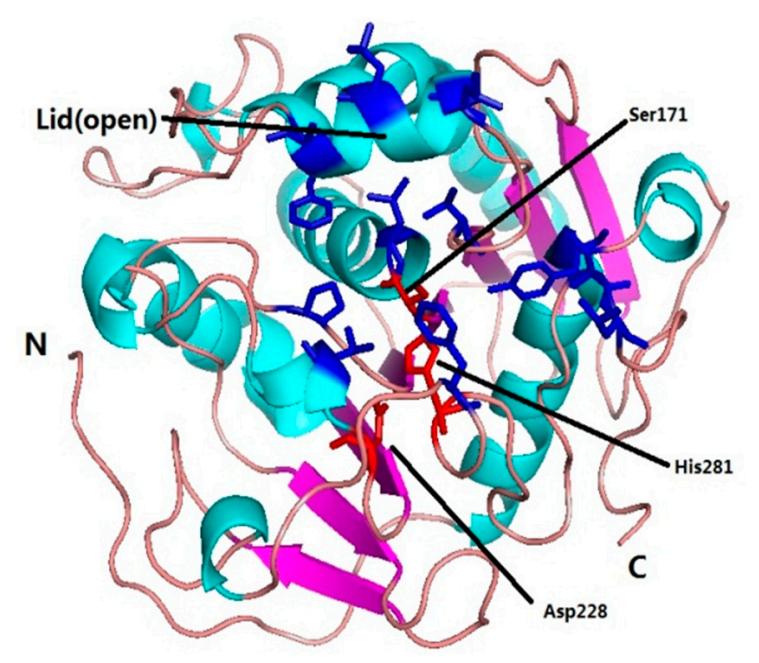

Figure 6. Cartoon view of the modeled MgMDL2 in the open conformation. The catalytic pocket and the residues constituted the oxyanion hole highlighted in blue, while the catalytic triads were colored red.

In the optimized MgMDL2-1, 2-DAG analogue complex structure (Figure 7A), the distance between carboxyl carbon and $\mathrm{O} \gamma$ of Ser171 is $3.4 \AA$ (Figure $7 \mathrm{~B}$ ). While in the best conformation of $M g M D L 2-1,3-D A G$ analogue complex structure(Figure 7C) ,the distance between phosphorus atom (substitution of carboxyl carbon) and $\mathrm{O} \gamma$ of Ser171 is $2.7 \AA$ (Figure 7D). As shown in Figure 7A,C, the catalytic pocket was divided by the side chain of Asn102 and Phe278 into two separated parts, exposed a groove and a narrow tunnel. In MgMDL2-1, 2-DAG analogue complex structure, the sn-1 alkyl chain lies in the exposed groove while the sn- 2 moiety of substrate inserts into the narrow tunnel. However in MgMDL2-1, 3-DAG analogue complex structure, the sn-1 moiety of substrate inserts in the narrow tunnel and the sn-3 alkyl chain lies in the exposed groove. Both in MgMDL2-1, 2- and 1,3-DAG analogue complex structures the Phe 278 projects its side chain toward active site, thus the catalytic pocket does not have enough space to accommodate the third chain of TAG, and therefore MgMDL2 can only catalyze the MAG and DAG but not TAG. This observation was similar with that of DAG-like lipase from $P$. cyclopium and A. oryzae [11,17].

In this study, we described cloning, expression and biochemical characterization of a putative DAG-like lipase from $M$. globosa. Recombinant MgMDL2 was found to be a glycosylated protein. It is reported that recombinant proteins having $N$-glycosylation sites (Asn-Xaa-Ser/Thr) produced in $P$. pastoris are often modified by glycosylation [18]. Despite increase of the molecular mass of recombinant proteins, glycosylation is an important post-translational modification that can affect proteins folding, stability, activity and half-life [19]. 

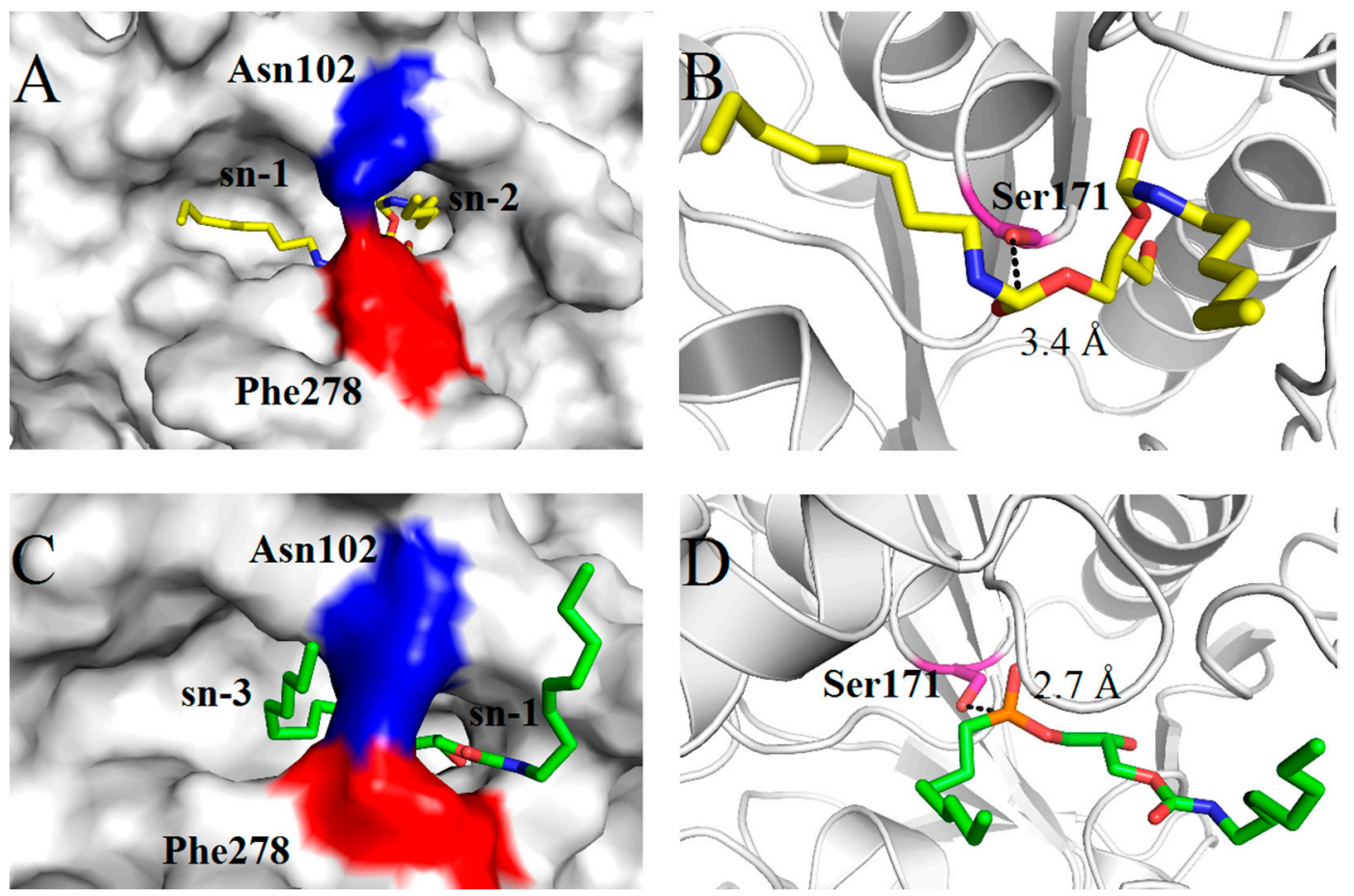

Figure 7. The 3-D structures of MgMDL2-DAG analogue complexes. (A) Surface view of the optimized MgMDL2-1, 2-DAG analogue; (B) A close-up view showing the distance from 1, 2-DAG analogue carboxyl carbon to O $\gamma$ of Ser171 in MgMDL2; (C) Surface view of the optimized MgMDL2-1, 3-DAG analogue; (D) A close-up view showing the distance from 1, 3-DAG analogue phosphorus atom (substitution of carboxyl carbon) to O $\gamma$ of Ser171 in $M g$ MDL2.

MgMDL2 showed highest activity at $15{ }^{\circ} \mathrm{C}$, and it retained more than $50 \%$ activity at $5{ }^{\circ} \mathrm{C}$. These properties were similar with that of cold active lipolitic enzyme reported in literatures [20,21]. Although cold active enzymes have many potential applications in industry, most of them have been reported to be unstable at high temperature. Lipase from Psychrobacter sp. strain in antarctic sea water completely lost its activity by incubation at 40 and $50{ }^{\circ} \mathrm{C}$ for $20 \mathrm{~min}$ [22]. h1Lip1 from uncultured bacteria of marine sediment was unstable at $25{ }^{\circ} \mathrm{C}$ and its half-life at $40{ }^{\circ} \mathrm{C}$ was less than $5 \mathrm{~min}$ [23]. M37 lipase from Photobacterium lipolyticum sp. was inactive after heat treatment (above $35^{\circ} \mathrm{C}$ ) for $20 \mathrm{~min}[24]$. In contrast, $M g$ MDL2 was stable after incubation of 30 and $40{ }^{\circ} \mathrm{C}$ for $2.5 \mathrm{~h}$, retaining more than $80 \%$ original activity.

MgMDL2 was found to be stable in the presence of methanol and ethanol at a concentration of $30 \%$ for $2 \mathrm{~h}$, indicating that MgMDL2 is a solvent tolerant enzyme. MgMDL2 was sensitive toward metal ions, such as $\mathrm{Ca}^{2+}, \mathrm{Mn}^{2+}$ and $\mathrm{Ni}^{2+}$, which hardly decrease its activity. In contrast, $\mathrm{Ca}^{2+}$ and $\mathrm{Mn}^{2+}$ was reported to simulate the activity of lipase from Bacillus sphaericus 205y [25], Pseudomonas aeruginosa LX1 [26] and Fusarium solani N4-2 [27]. The lipase lost 32\% of its activity in presence of 5 mM EDTA, indicating that $\mathrm{MgMDL} 2$ might be a metallohydrolase. Structural analysis of MgMDL2 showed that Phe278 might involve in unique substrate selectivity of $M g$ MDL2. The position and orientation of the phenylalanine seem to be a common phenomenon to DAG-like lipases. For DAG-like lipase from P. cyclopium, Phe256 was predicted to play an important role in substrate selectivity [17], while 
"bridge-like" structure constituted by two bulky residues (W89 and F257) on the top of catalytic site in A. oryzae lipase, which prevented substrates with large size from entering the active site [11].

\section{Experimental Section}

\subsection{Strains, Plasmids, Chemicals and Materials}

Escherichia coli Top10 (Invitrogen, Carlsbad, CA, USA) was used as cloning host. The plasmid pGAPZ $\alpha$ A and $P$. pastoris X-33 strain (Invitrogen, Carlsbad, CA, USA) are used for gene cloning and expression, respectively. The $p$-nitrophenol and $p$-nitrophenol ( $p$ np) ester derivates were purchased from Sigma-Aldrich. $n$-hexane and 2-propanol were of HPLC grade from Kermel Chemical Reagent Co., Ltd. (Tianjin, China).

DAG-rich acylglycerols used in this study were synthesized by enzymatic esterification of glycerol and FFAs in our laboratory. At first, free fatty acids (FFAs) were produced by enzymatic hydrolysis of camellia oil using Palatase 20000L (Novo Nordisk A/S, Bagsvaerd, Denmark), and then the FFA was further purified by molecular distillation. P. camembertii lipase, a DAG-like liapse, was used for synthesis of DAG and MAG by esterification of glycerol and FFAs, and then the products were further purified by molecular distillation. The content of DAG-rich oil $(23.47 \%$ of 1,2-DAG, $47.60 \%$ of 1,3-DAG, $21.51 \%$ of MAG and $7.42 \%$ of FFA) was analyzed by HPLC. Camellia oil (TAG, 99\%) was purchased from the local market in China. Other chemicals were of analytical grade.

\subsection{Vector Construction and Transformation of P. pastoris}

The MgMDL2 gene (915 bp) derived from M. globosa (GenBank accession number: XM_001732154) was artificially synthesized according to the code usage of $P$. pastoris by Sangon Biotech, Inc. (Shanghai, China). The gene encoding the mature peptide (58 to $915 \mathrm{bp}$, without signal peptide region) was cloned into pGAPZ $\alpha$ A (Invitrogen, Carlsbad, CA, USA) vector pGAPZ $\alpha$ A-Mgmdl2 was confirmed by DNA sequencing and then linearized by restriction enzyme Bln I. The purified linearized DNA was transformed into $P$. pastoris X-33 strain by electroporation. The transformants were selected on YPD $\left(1 \%(w / v)\right.$ yeast extract, $2 \%(w / v)$ peptone and 2\% $(w / v)$ glucose) plates containing Zeocin ${ }^{\mathrm{TM}}$ $(100 \mu \mathrm{g} / \mathrm{mL})$ at $30{ }^{\circ} \mathrm{C}$ for three days until the colony formed.

\subsection{Expression and Purification of Recombinant Enzyme}

The $P$. pastoris $\mathrm{X}-33$ transformants containing the recombinant vector were grown and expressed in YPD medium at $30{ }^{\circ} \mathrm{C}$ with shaking of $200 \mathrm{rpm}$ for $72 \mathrm{~h}$. The supernatant of fermentation broth was collected by centrifugation $\left(10,000 \times \mathrm{g}, 20 \mathrm{~min}, 4^{\circ} \mathrm{C}\right)$ and filtered through a $0.45 \mu \mathrm{m}$ filter membrane. The resulting supernatant of fermentation broth was concentrated and buffer-exchanged to buffer $\mathrm{A}$ (20 mM Tris- $\mathrm{HCl}, \mathrm{pH} 8.0$, at $4{ }^{\circ} \mathrm{C}$ ) using a crossflow cassette with a $10 \mathrm{kDa}$ cutoff membrane (Vivaflow 200, Sartorius, Germany). The recombinant MgMDL2 were purified form the fermentation broth by anion exchange chromatography. Sample in Buffer A was loaded into the Q-Sepharose Fast Flow column and washed with a linear ion gradient $(300 \mathrm{~mL}$ of $0-200 \mathrm{mM} \mathrm{NaCl}$ in buffer $\mathrm{A})$. The fraction containing purified lipases were collected and analyzed by $12 \%$ SDS-PAGE. Protein concentrations were determined by the BCA Protein Assay Kit (Sangon Biotech, Shanghai Co., Ltd., Shanghai, China). 


\subsection{Biochemical Characterization of Recombinant Enzyme}

\subsubsection{Enzyme Activity Determination}

The enzyme activity was determined by colorimetric method using $p$-nitrophenyl esters as substrate $[28,29]$. One unit of enzyme activity is defined as the amount of enzyme required to release $1 \mu \mathrm{mol}$ of $p$-nitrophenol per minute.

\subsubsection{Determining Temperature-Optimum of Activity and Thermostability of Lipase}

The optimum temperature of the lipase was evaluated at $\mathrm{pH} 6.0$ using $p$ np caprylate as substrate. The temperatures were set as $5,10,15,20,25$ and $30^{\circ} \mathrm{C}$.

The thermostability of $M g$ MDL2 was tested by pre-incubating the MgMDL2 at different temperatures for $2.5 \mathrm{~h}$. In addition, samples were taken at intervals of $30 \mathrm{~min}$ for measurement of residual activity under the above assay conditions ( $\mathrm{pH} \mathrm{6.0,} \mathrm{optimum} \mathrm{temperature).} \mathrm{The} \mathrm{temperatures} \mathrm{were} \mathrm{set} \mathrm{as} \mathrm{30,}$ 40 and $50^{\circ} \mathrm{C}$.

\subsubsection{Determining $\mathrm{pH}-\mathrm{Optimum}$ of Activity and $\mathrm{pH}$ Stability of Lipase}

Optimum $\mathrm{pH}$ for the $\mathrm{MgMDL} 2$ was determined at $15{ }^{\circ} \mathrm{C}$ using $p$ np caprylate as substrate. The buffers used in this study included $100 \mathrm{mM}$ sodium citrate, $100 \mathrm{mM}$ citric acid (pH 4 and 5), $100 \mathrm{mM}$ phosphate buffer (pH 6 and 7), $50 \mathrm{mM}$ Tris- $\mathrm{HCl}$ (pH 8.0) and $50 \mathrm{mM}$ Gly-NaOH (pH 9.0).

The $\mathrm{pH}$ stability of lipase was determined by pre-incubating enzymes in different $\mathrm{pH}$ buffers (from $\mathrm{pH} 4.0$ to 9.0 ) for $12 \mathrm{~h}$ at $4{ }^{\circ} \mathrm{C}$, and then the residual activity was determined at $15{ }^{\circ} \mathrm{C}$ at $\mathrm{pH} 6.0$.

\subsubsection{Substrates Specificity}

$p$ np esters and acylglycerol were used to analyze the substrates specificity of $M g$ MDL2. $p$ np esters with different chain length (C4-C18) was used as substrates $(10 \mathrm{mM}$, dissolved in ethanol). Hydrolytic reaction was performed at $15^{\circ} \mathrm{C}$ and $\mathrm{pH} 6.0$.

For hydrolysis of acylglycerol, DAG-rich oil and camellia oil (TAG) were used. The hydrolytic reactions were performed in a $15 \mathrm{~mL}$ conical flask with stirring at $200 \mathrm{rpm}$. The reaction mixture includes water ( $25 \%$ content with respect to oil), purified enzyme (12 U/g, with respect to oil), and the optimal temperature were used. Aliquots $(150 \mu \mathrm{L})$ of the reaction mixture were periodically withdrawn and then were centrifuged at $10,000 \times g$ for $3 \mathrm{~min}$ to remove the water in the upper layer. Twenty $\mu \mathrm{L}$ of supernatant were diluted in $1 \mathrm{~mL}$ of $n$-hexane/2-propanol/methanoic acid (15:1:0.003 $v / v / v)$ for HPLC analysis [30].

\subsubsection{Effect of Metal Ions on the Enzyme Activity}

The influence of metal ions on the lipase activity was determined in the presence of various metal ions. Enzyme activity was tested at $15^{\circ} \mathrm{C}$ and $\mathrm{pH} 6.0$ using pnp caprylate as substrate. Metal ions including $\mathrm{ZnSO}_{4}, \mathrm{MgSO}_{4}, \mathrm{FeCl}_{2}, \mathrm{CaCl}_{2}, \mathrm{MnSO}_{4}$ and $\mathrm{NiCl}_{2}$ at a final concentration of $5 \mathrm{mM}$ were used in this study. The effect of ethylenediaminetetraacetic acid (EDTA) on enzyme activity was also investigated as described as above. 


\subsubsection{Effect of Organic Solvents on the Enzyme Activity}

The effect of various organic solvents (methanol, ethanol, acetone and isopropanol) on lipase activity was determined. The lipase solution was incubated separately with each organic solvent (final concentration $30 \%, v / v$ ) at $4{ }^{\circ} \mathrm{C}$ for $2 \mathrm{~h}$, and then the residual activity of enzyme was measured at $15^{\circ} \mathrm{C}$ and pH 6.0 using pnp caprylate as substrate.

\subsubsection{Detection of Glycolysation Modification}

Deglycolysation of purified MgMDL2 was performed by using glycopeptidase F kit (Takara Company, Dalian, China) according to the instruction of manufacturer. Briefly, recombinant MgMDL2 $(25 \mu \mathrm{g})$ was denatured by incubation at $100^{\circ} \mathrm{C}$ for $3 \mathrm{~min}$ in a denature buffer. In addition, the resulting MgMDL2 was mixed with glycopeptidase F (1 mU) in reaction buffer and incubated at $37{ }^{\circ} \mathrm{C}$ for $15 \mathrm{~h}$. The reaction product was analyzed by $12 \%$ SDS-PAGE.

\subsection{Sequence and Structure Analysis}

\subsubsection{Sequence Analysis}

Similarity searches were performed with BLAST 2.0 program [31]. Prediction of signal peptide of MgMDL2 was carried out by SignalP 4.1 Server [32]. The putative glycosylation sites were searching by NetNGlyc 1.0 Server. Multiple sequence alignments were performed with ClustalW2 [33] and ESPript [34].

\subsubsection{Construction of the Structure in the Open Conformation}

The core domain of MgMDL2 (residues 20-100, 119-304) was constructed by the crystal structure of SMG1 (PDB ID: 3UUE) [12]. The lid domain in open conformation was homologically modeled based on the crystal structure of Rhizomucor miehei lipase (RML) in complex with the diethyl pnp phosphonate (PDB ID: 4TGL) [14]. All of above processes were performed by the Discovery Studio. VERIFY-3D (Discovery Studio, Accelrys Inc., San Diego, CA, USA) was used to validate the refined model of $M g$ MDL2.

\subsubsection{Construction of a Model in Complex with Substrate Analogue}

A 1,2- and 1,3-diacylglycerol analogues were extracted from the crystal structure of Pseudomonas aeruginosa lipase (PDB: 1EX9) by removing the sn-3 or sn-2 respectively [35]. Molecular dynamics (MD) were carried out to fully relax the steric clashes occurred in this enzyme-substrate analogue complex.

\subsubsection{Simulations}

The MD simulations were performed by the Discovery Studio package. The MgMDL2-1,2- and 1,3-DAG analog complexes were solved in an orthorhombic box with 7940 and 7979 water molecules respectively and simulated with periodic boundary conditions. After twice energy minimizations, 
the final RMS gradient converged to $0.0001 \mathrm{kcal} /(\mathrm{mol} \times \AA)$. The Particle Mesh Ewald algorithm was applied to the following simulations. The system was heated from 50 to $300 \mathrm{~K}$ for 2000 steps ( $0.001 \mathrm{ps}$ per step) and equilibrated at $300 \mathrm{~K}$ for 1000 steps ( 0.001 ps per step). Production simulations were worked at $300 \mathrm{~K}$ for 5000 steps ( 0.001 ps per step). All the processes used the CHARMM force field. The optimized 3-D structure of MgMDL2-substrate analogues were visualized using the PyMOL software.

\section{Conclusions}

DAG-like lipases are kinds of enzymes that are found to be important in life science and have potential in industrial applications. However, few works have been done on them. Here, the other enzyme (MgMDL2) from M. globosa was researched. MgMDL2 was identified to be a typical DAG-like lipase which shows activity on MAG and DAG not on TAG. MgMDL2 was a cold active lipase with optimal activity at $15{ }^{\circ} \mathrm{C}$ and it kept over $50 \%$ of relative activity at $5{ }^{\circ} \mathrm{C}$. By modeling MgMDL2 in open conformation, a DAG analogue was docked into the catalytic pocket to get the optimized MgMDL2-DAG analogue complex structure. Phe278 was predicted to be involved in substrate specificity of MgMDL2. Here, we have described a novel cold-active DAG-like lipase which is a potential biocatalyst for industrial application such as, oil modification, biodiesel, food, detergent and pharmaceutical industry. Our work also shed some light on understanding the structural-functional relationship of DAG-like lipases.

\section{Acknowledgments}

This work was supported by the National Science Funds for the Excellent Youth Scholars (31222043), National Natural Science Foundation of China (21406076), research fund for the Doctoral Program of Higher Education of China (20130172120014) and research funds for the Central Universities (2013ZM0068).

\section{Author Contributions}

Huan $\mathrm{Xu}$ designed the study, expressed the enzyme, measured the enzyme activity and co-wrote the paper; Dongming Lan analyzed the data and co-wrote the paper; Bo Yang prepared the DAG-rich oil and measured the enzyme activity; Yonghua Wang conceived and co-designed the study, advised on experiments and co-wrote the paper.

\section{Conflicts of Interest}

The authors declare no conflict of interest.

\section{References}

1. Bisogno, T.; Howell, F.; Williams, G.; Minassi, A.; Cascio, M.G.; Ligresti, A.; Matias, I.; Schiano-Moriello, A.; Paul, P.; Williams, E.J.; et al. Cloning of the first sn1-DAG lipases points to the spatial and temporal regulation of endocannabinoid signaling in the brain. J. Cell Biol. 2003, $163,463-468$. 
2. Kohnz, R.A.; Nomura, D.K. Chemical approaches to therapeutically target the metabolism and signaling of the endocannabinoid 2-AG and eicosanoids. Chem. Soc. Rev. 2014, 43, 6859-6869.

3. Xu, D.; Sun, L.J.; Chen, H.Y.; Lan, D.M.; Wang, Y.H.; Yang, B. Enzymatic synthesis of diacylglycerols enriched with conjugated linoleic acid by a novel lipase from Malassezia globosa. J. Am. Oil Chem. Soc. 2012, 89, 1259-1266.

4. Wang, W.F.; Li, T.; Qin, X.L.; Ning, Z.X.; Yang, B.; Wang, Y.H. Production of lipase SMG1 and its application in synthesizing diacylglyecrol. J. Mol. Catal. B 2012, 77, 87-91.

5. Yamaguchi, S.; Takeuchi, K.; Mase, T.; Matsuura, A. Efficient expression of mono- and diacylglycerol lipase gene from Penicillium camembertii U-150 in Aspergillus oryzae under the control of its own promoter. Biosci. Biotechnol. Biochem. 1997, 61, 800-805.

6. Chahinian, H.; Vanot, G.; Ibrik, A.; Rugani, N.; Sarda, L.; Comeau, L.C. Production of extracellular lipases by Penicillium cyclopium purification and characterization of a partial acylglycerol lipase. Biosci. Biotechnol. Biochem. 2000, 64, 215-222.

7. Mase, T.; Matsumiya, Y.; Akiba, T. Purification and characterization of a new lipase from fusarium sp ym-30. Biosci. Biotechnol. Biochem. 1995, 59, 1771-1772.

8. Toida, J.; Kondoh, K.; Fukuzawa, M.; Ohnishi, K.; Sekiguchi, J. purification and characterization of a lipase from aspergillus-oryzae. Biosci. Biotechnol. Biochem. 1995, 59, 1199-1203.

9. Tsuchiya, A.; Nakazawa, H.; Toida, J.; Ohnishi, K.; Sekiguchi, J. Cloning and nucleotide sequence of the mono- and diacylglycerol lipase gene (mdlB) of Aspergillus oryzae. FEMS Microbiol. Lett. 1996, 143, 63-67.

10. DeAngelis, Y.M.; Saunders, C.W.; Johnstone, K.R.; Reeder, N.L.; Coleman, C.G.; Kaczvinsky, J.R., Jr.; Gale, C.; Walter, R.; Mekel, M.; Lacey, M.P.; et al. Isolation and expression of a Malassezia globosa lipase gene, LIP1. J. Investig. Dermatol. 2007, 127, 2138-2146.

11. Liu, L.; Lan, D.M.; Wang, Q.; Gao, C.L.; Li, Z.G.; Yang, B.; Wang, Y.H. A “bridge-like” structure responsible for the substrate selectivity of mono- and diacylglycerol lipase from Aspergillus oryzae. J. Mol. Catal. B 2013, 97, 144-149.

12. Xu, T.; Liu, L.; Hou, S.; Xu, J.; Yang, B.; Wang, Y.; Liu, J. Crystal structure of a mono- and diacylglycerol lipase from Malassezia globosa reveals a novel lid conformation and insights into the substrate specificity. J. Struct. Biol. 2012, 178, 363-369.

13. Derewenda, U.; Swenson, L.; Green, R.; Wei, Y.; Dodson, G.G.; Yamaguchi, S.; Haas, M.J.; Derewenda, Z.S. An unusual buried polar cluster in a family of fungal lipases. Nat. Struct. Biol. 1994, 1, 36-47.

14. Derewenda, U.; Brzozowski, A.M.; Lawson, D.M.; Derewenda, Z.S. Catalysis at the interface: The anatomy of a conformational change in a triglyceride lipase. Biochemistry (Mosc.) 1992, 31, $1532-1541$.

15. Derewenda, U.; Swenson, L.; Wei, Y.; Green, R.; Kobos, P.M.; Joerger, R.; Haas, M.J.; Derewenda, Z.S. Conformational lability of lipases observed in the absence of an oil-water interface: Crystallographic studies of enzymes from the fungi Humicola lanuginosa and Rhizopus delemar. J. Lipid Res. 1994, 35, 524-534.

16. Skropeta, D. The effect of individual $N$-glycans on enzyme activity. Bioorg. Med. Chem. 2009, 17, 2645-2653. 
17. Tan, Z.B.; Li, J.F.; Li, X.T.; Gu, Y.; Wu, M.C.; Wu, J.; Wang, J.Q. A unique mono- and diacylglycerol lipase from Penicillium cyclopium: Heterologous expression, biochemical characterization and molecular basis for its substrate selectivity. PLoS One 2014, 9, e102040.

18. Cereghino, J.L.; Cregg, J.M. Heterologous protein expression in the methylotrophic yeast Pichia pastoris. FEMS Microbiol. Rev. 2000, 24, 45-66.

19. Solá, R.J.; Griebenow, K. Effects of glycosylation on the stability of protein pharmaceuticals. J. Pharm. Sci. 2009, 98, 1223-1245.

20. Kavitha, M.; Shanthi, C. Isolation and Characterization of Cold active lipase producing Pseudomonas sp 4 from Marine samples of Tamilnadu Coast. Res. J. Biotechnol. 2013, 8, 57-62.

21. Jeon, J.H.; Kim, J.T.; Kim, Y.J.; Kim, H.K.; Lee, H.S.; Kang, S.G.; Kim, S.J.; Lee, J.H. Cloning and characterization of a new cold-active lipase from a deep-sea sediment metagenome. Appl. Microbiol. Biotechnol. 2009, 81, 865-874.

22. Parra, L.P.; Reyes, F.; Acevedo, J.P.; Salazar, O.; Andrews, B.A.; Asenjo, J.A. Cloning and fusion expression of a cold-active lipase from marine Antarctic origin. Enzym. Microb. Technol. 2008, 42, 371-377.

23. Hårdeman, F.; Sjöling, S. Metagenomic approach for the isolation of a novel low-temperature-active lipase from uncultured bacteria of marine sediment. FEMS Microbiol. Ecol. 2007, 59, 524-534.

24. Ryu, H.; Kim, H.; Choi, W.; Kim, M.; Park, S.; Han, N.; Oh, T.; Lee, J. New cold-adapted lipase from Photobacterium lipolyticum sp. nov. that is closely related to filamentous fungal lipases. Appl. Microbiol. Biotechnol. 2006, 70, 321-326.

25. Sulong, M.R.; Zaliha Raja Abd Rahman, R.N.; Salleh, A.B.; Basri, M. A novel organic solvent tolerant lipase from Bacillus sphaericus 205y: Extracellular expression of a novel OST-lipase gene. Protein Expr. Purif. 2006, 49, 190-195.

26. Ji, Q.; Xiao, S.; He, B.; Liu, X. Purification and characterization of an organic solvent-tolerant lipase from Pseudomonas aeruginosa LX1 and its application for biodiesel production. J. Mol. Catal. B 2010, 66, 264-269.

27. Liu, R.; Jiang, X.; Mou, H.; Guan, H.; Hwang, H.; Li, X. A novel low-temperature resistant alkaline lipase from a soda lake fungus strain Fusarium solani N4-2 for detergent formulation. Biochem. Eng. J. 2009, 46, 265-270.

28. Gao, C.; Lan, D.; Liu, L.; Zhang, H.; Yang, B.; Wang, Y. Site-directed mutagenesis studies of the aromatic residues at the active site of a lipase from Malassezia globosa. Biochimie 2014, 102, 29-36.

29. Kanwar, S.S.; Kaushal, R.K.; Jawed, A.; Gupta, R.; Chimni, S.S. Methods for inhibition of residual lipase activity in colorimetric assay: A comparative study. Indian J. Biochem. Biophys. 2005, 42, 233-237.

30. Xu, Y.; Guo, S.H.; Wang, W.F.; Wang, Y.H.; Yang, B. Enzymatic hydrolysis of palm stearin to produce diacylglycerol with a highly thermostable lipase. Eur. J. Lipid Sci. Technol. 2013, 115, 564-570.

31. Boratyn, G.M.; Camacho, C.; Cooper, P.S.; Coulouris, G.; Fong, A.; Ma, N.; Madden, T.L.; Matten, W.T.; McGinnis, S.D.; Merezhuk, Y.; et al. BLAST: A more efficient report with usability improvements. Nucleic Acids Res. 2013, 41, W29-W33. 
32. Petersen, T.N.; Brunak, S.; von Heijne, G.; Nielsen, H. SignalP 4.0: Discriminating signal peptides from transmembrane regions. Nat. Methods 2011, 8, 785-786.

33. Larkin, M.A.; Blackshields, G.; Brown, N.P.; Chenna, R.; McGettigan, P.A.; McWilliam, H.; Valentin, F.; Wallace, I.M.; Wilm, A.; Lopez, R.; et al. Clustal W and Clustal X version 2.0. Bioinformatics 2007, 23, 2947-2948.

34. Gouet, P.; Courcelle, E.; Stuart, D.I.; Metoz, F. ESPript: Analysis of multiple sequence alignments in PostScript. Bioinformatics 1999, 15, 305-308.

35. Nardini, M.; Lang, D.A.; Liebeton, K.; Jaeger, K.E.; Dijkstra, B.W. Crystal structure of pseudomonas aeruginosa lipase in the open conformation. The prototype for family I.1 of bacterial lipases. J. Biol. Chem. 2000, 275, 31219-31225.

(C) 2015 by the authors; licensee MDPI, Basel, Switzerland. This article is an open access article distributed under the terms and conditions of the Creative Commons Attribution license (http://creativecommons.org/licenses/by/4.0/). 